\title{
Octadecylamine, 1,2,3-benzotriazole and a mixture thereof as chamber inhibitors of steel corrosion ${ }^{1}$
}

\section{O.A. Goncharova, A.Yu. Luchkin, Yu.I. Kuznetsov, N.N. Andreev, * N.P. Andreeva and S.S. Vesely}

\author{
A.N. Frumkin Institute of Physical Chemistry and Electrochemistry, Russian Academy \\ of Sciences, Leninsky pr. 31, Moscow, 119071 Russian Federation \\ *E-mail: n.andreev@mail.ru
}

\begin{abstract}
It has been shown that it is possible to create a technology for efficient protection of steel items by short-term treatment in vapors of low-volatile corrosion inhibitors in specialized chambers at elevated temperatures. It is suggested to call this technology based on the protection after-effect of adsorbed inhibitor films as "chamber treatment" and the compounds used therein as "chamber inhibitors". A number of methods (accelerated and field corrosion tests, potentiodynamic polarization measurements, ellipsometry, surface wetting angle measurement) were used to study the formation of adsorption films of 1,2,3benzotriazole (BTA), octadecylamine (ODA), and a mixture thereof on steel from a gas phase. It has been found that the temperature plots of the protection after-effect of the inhibitors studied have a maximum at $120^{\circ} \mathrm{C}$. The adsorption films that stabilize the passive state of steel (both in the absence of chloride and in chloride-containing electrolytes) and noticeably hydrophobize the surface are already formed within one hour of chamber treatment. The adsorption films of ODA and its mixtures with BTA hinder steel corrosion initiation under conditions of recurrent moisture condensation more than 100 -fold and have significantly better protective properties than the adsorption films of BTA. It has been found that adsorption of inhibitors hinders the thermal oxidation of steel. The total thickness of the surface layers on steel (oxide film and adsorbed inhibitor) responsible for the protection after-effect depends on the inhibitor nature but does not exceed $15 \mathrm{~nm}$. It has been shown that treatment in vapors of ODA or its mixture with BTA markedly increases the corrosion resistance of low-carbon steel under weathering conditions and can be used for the interoperational protection of metal items.
\end{abstract}

Received: May 1, 2018. Published: May 23, 2018

doi: $\underline{10.17675 / 2305-6894-2018-7-2-7}$

Key words: corrosion inhibitors, vapor-phase protection, temporary protection, chamber treatment.

\footnotetext{
${ }^{1}$ This study was financially supported by the Russian Science Foundation (RSF) grant no.17-13-01413 "Fundamental aspects of formation of ultrathin passivating films from organic compounds in protection from atmospheric corrosion".
} 


\section{Introduction}

The temporary protection of metal items from atmospheric corrosion is an important technical issue [1-3]. The use of volatile corrosion inhibitors (VCIs) is among the methods used to solve it [3-6]. Numerous publications, including [6-14], deal with the theory and practice of metal protection by VCIs.

Analysis of these publications shows that the main condition of VCI application involves the possibility to pack the items and VCI source together into the same airtight encasement for the period of transportation and/or storage of the items. The publications mentioned above provide the following overall picture of VCI operation. Owing to the high vapor pressure, the VCIs vaporize spontaneously, saturate the volume being protected, reach the metal in vapor form, and form thin (nanosized) protective adsorption films on its surface before corrosion spots can appear on the metal.

During the protection period, these films are in dynamic equilibrium with the internal atmosphere of the packing. VCI molecules are continuously desorbed and evaporated from the metal surface. Desorption is replenished by adsorption of the VCI from the volume being protected, which is saturated with inhibitor vapors.

The equilibrium is violated if the packing loses air-tightness. The VCI is desorbed and evaporates from the surface and from the volume being protected, thus protection is violated. The main prerequisite of VCI applicability is simultaneously the main drawback of the classical variant of metal vapor-phase protection by inhibitors. In practice, it is not always possible to maintain the air-tightness of a barrier packing.

However, corrosion is not initiated instantly when the packing integrity is broken. VCIs capable of chemisorption can have rather a long protection after-effect (PAE). Other conditions being equal, its duration increases with a decrease in the saturated vapor pressure of the inhibitor. Unfortunately, the formation of protective adsorption films from low-volatile compounds occurs slowly, so corrosion can damage the metal even before such films are formed.

A way out of this situation that ensures the fast formation of protective layers and a long-term protection after-effect is to use the so-called chamber treatment (CT). It involves a short-term treatment of a metal in specialized chambers by vapors of low-volatile inhibitors at elevated temperatures $(t)$ where their vapor pressure increases manyfold. During chamber treatment, adsorption films are formed on a metal from the vapor phase. They slowly vaporize from the surface at temperatures typical of storage and transportation conditions and thus can protect the metal for a long period of time. This eliminates the necessity to pack the metal and inhibitor together for the protection period. In this version of vapor-phase protection, the metal protection is provided by the after-effect. The prospects of this approach have been demonstrated in [15].

The purpose of this study was to estimate the properties of adsorption films formed on steel during chamber treatment with octadecylamine (ODA), 1,2,3-benzotriazole (BTA), and their mixture $(1: 1 \mathrm{~m} / \mathrm{m})$. 


\section{Experimental}

We studied the properties of adsorption films formed on St3 steel with the following composition: $\mathrm{Fe}>98$; $\mathrm{C} 0.14-0.22$; $\mathrm{Mn} 0.4-0.65$; $\mathrm{Ni}<0.3$; $\mathrm{Cr}<0.3$; $\mathrm{Cu}<0.3$; Si 0.05$0.15 ;$ As $<0.08 ; \mathrm{S}<0.05 ; \mathrm{P}<0.04 ; \mathrm{N}<0.008$.

Corrosion tests, ellipsometric measurements and wetting angle determinations were performed using flat rectangle specimens $(40 \times 50 \times 1.5 \mathrm{~mm})$.

Potentiodynamic studies were performed using cylindrical electrodes with a diameter of $10 \mathrm{~mm}$ embedded in Teflon on its side walls. One of the butt ends of each electrode had a threaded hole for the mounting rod, while the other butt end served as the working surface.

Before the tests, the specimens and electrodes were cleaned with emery papers to a mirror gloss, wiped with acetone, dried in air, and kept for $24 \mathrm{~h}$ in a desiccator over calcinated $\mathrm{CaCl}_{2}$.

Prior to CT, specimens and electrodes were mounted in airtight $0.5 \mathrm{~L}$ cells (chambers). The chamber inhibitor (ChIn, $0.5 \mathrm{~g}$ ) was also placed into each cell. After that, the cells were placed into a preheated drying cabinet. The CT temperature $\left(t_{\mathrm{ct}}\right)$ and duration $\left(\tau_{\mathrm{ct}}\right)$ are reported in the text below. After thermal treatment, the cells were removed from the cabinet, cooled and kept for $24 \mathrm{~h}$ at room temperature. After that, the specimens and/or electrodes were withdrawn from the cells and tested.

Accelerated corrosion tests were carried out under recurrent moisture condensation conditions. Specimens were mounted in $0.6 \mathrm{~L}$ glass cells. Water heated to $50^{\circ} \mathrm{C}(0.1 \mathrm{~L})$ was poured on the bottom of each cell. Once every 24 hours, the cooled water was replaced with hot water. Specimens were visually inspected every hour during the first day of the test and then once a day.

In the field corrosion tests, specimens were stored at the Moscow corrosion station under a shelter preventing direct exposure to atmospheric precipitation.

The time until the appearance of the first corrosion damage on the metal $\left(\tau_{\mathrm{pr}}\right)$ served as the criterion of the CT efficiency in the tests described above.

Potentiodynamic experiments were carried out in borate buffer solution ( $\mathrm{pH} \mathrm{7.36)}$ containing $0.001 \mathrm{M}$ sodium chloride. An IPC-pro potentiostat (RF) connected to a computer and a standard three-electrode cell were used. A platinum auxiliary electrode and a silver/silver chloride reference electrode were employed. The measured potentials $(E)$ were converted to the normal hydrogen scale. Electrodes were placed into a cell containing the electrolyte, kept for $5 \mathrm{~min}$ and polarized from the $E$ that was established $\left(E_{\mathrm{st}}\right)$ in the anodic or cathodic direction at a scan rate of $0.2 \mathrm{mV} / \mathrm{s}$.

In case of anodic polarization, the potential of local anionic depassivation $\left(E_{\mathrm{ld}}\right)$ was recorded. It was detected based on a sharp increase in the anodic current density $(i)$ or its oscillations on the polarization curves. Recording of anodic curves was interrupted once $i$ reached $0.05 \mathrm{~mA} / \mathrm{cm}^{2}$. Cathodic polarization was performed to a potential of $E=-0.5 \mathrm{~V}$. 
The thicknesses $(d)$ of the films formed on the metals were calculated from ellipsometric angles $\Delta$ and $\Psi$ using the ELLIPSHEET tool (E. Kondoh) [16] in the threelayer model approximation. The $\Delta$ and $\Psi$ angles were measured with a Gartner manual ellipsometer with light beam modulation and advanced light detection. An LSM-S-111-10NNP25 solid-state laser with diode pumping and a wavelength of $540 \mathrm{~nm}$ was used as the radiation source.

The angles of wetting $(\theta)$ of steel surface by distilled water were estimated for a droplet $0.002-0.003 \mathrm{ml}$ in volume. A droplet was placed on a specimen surface and a picture was taken. The $\theta$ values were determined in the images using PicPick graphic editor.

\section{Results and Discussion}

The results of accelerated corrosion tests under conditions of recurrent moisture condensation on the specimens are presented in Figure 1. In these tests, the effect of $\tau_{\mathrm{ct}}$ and $t_{\mathrm{ct}}$ of steel treatment with inhibitors on the protection after-effect of adsorption films was studied in order to determine the optimum passivation conditions.
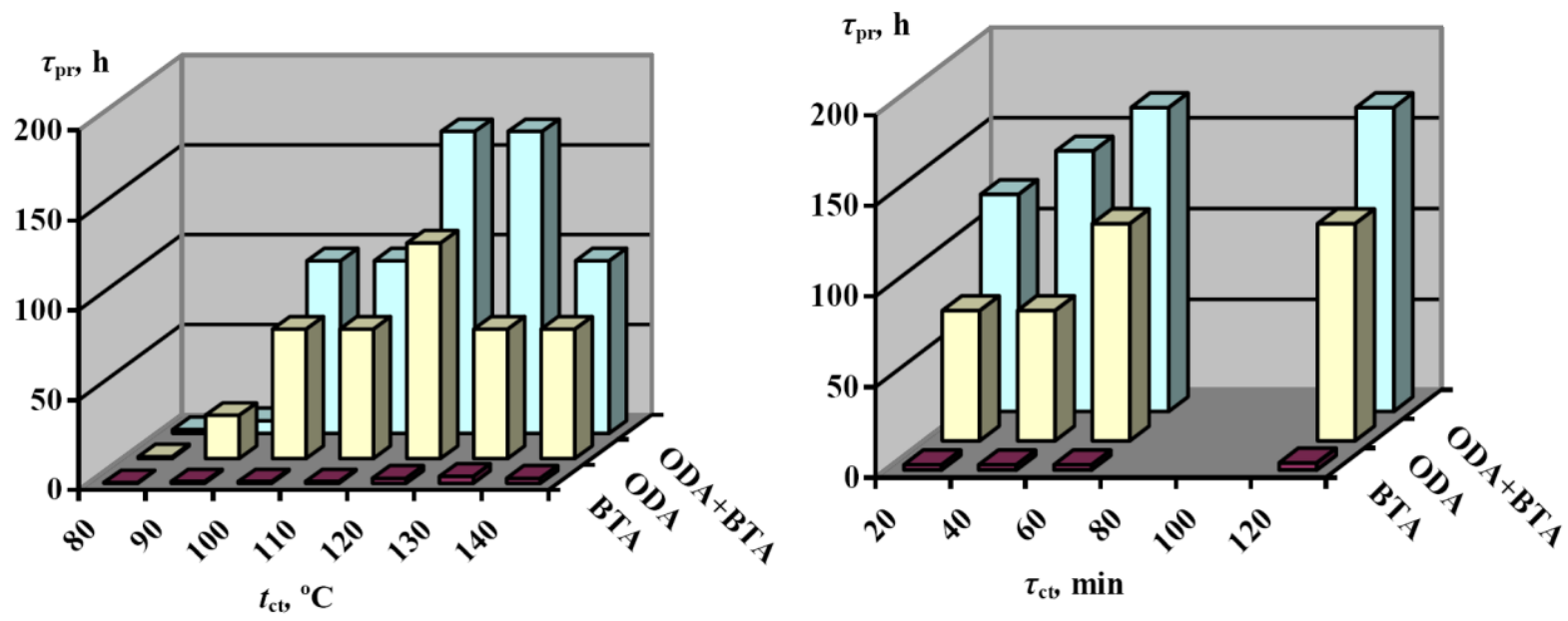

Figure 1. Effect of $t_{\mathrm{ct}}(\mathrm{a})$ and $\tau_{\mathrm{ct}}$ (b) on $\tau_{\mathrm{pr}}$ of steel under conditions of recurrent moisture condensation.

After hot water was added to a cell, its vapors began to condense intensely on the metal. This quickly resulted in corrosion of the specimens which were not treated with a ChIn. As early as in $1 \mathrm{~h}$, spots with a light rust layer appeared on the background specimens. It is important that the $\tau_{\mathrm{pr}}$ in the absence of ChIn weakly depended on the temperature of chamber treatment, the duration of which was $1 \mathrm{~h}$ in the first series of experiments (Figure 1a).

After chamber treatment of steel at $80^{\circ} \mathrm{C}$, any differences in the protection aftereffects of all the ChIn studied from those of the background specimens were within the experimental error. Increasing the $t_{\mathrm{ct}}$ to $100^{\circ} \mathrm{C}$ resulted in an abrupt increase in the $\tau_{\mathrm{pr}}$ on steel treated with vapors of ODA or its mixture with BTA. The latter demonstrated the maximum effect $(168 \mathrm{~h})$ at $120^{\circ} \mathrm{C}$. The mixed ChIn showed a somewhat weaker PAE 
$(96 \mathrm{~h})$ at steel $t_{\mathrm{ct}}$ of 100 or $140^{\circ} \mathrm{C}$. The PAE of ODA itself was inferior to that of the ODA+BTA mixture in the entire $t_{\mathrm{ct}}$ range. The PAE of ODA for 100 and $120^{\circ} \mathrm{C}$ amounted to 72 and $120 \mathrm{~h}$, respectively. At $t_{\mathrm{ct}}=140^{\circ} \mathrm{C}$, the PAE decreased to $72 \mathrm{~h}$ again. BTA did not demonstrate a considerable PAE in the entire $t_{\mathrm{ct}}$ range. The maximum $\tau_{\mathrm{pr}}$ of steel with this compound never exceeded $4 \mathrm{~h}$.

The existence of extremums on the PAE vs. temperature plots is apparently due to the interaction of two processes that differently affect the adsorption of ChIn vapors. On the one hand, the $p$ of inhibitors grows with an increase in $t$, which favors the adsorption of their vapors. On the other hand, as $t$ rises, the adsorption of gases (vapors) on solid sorbents becomes weaker [17].

Thus, like in the case of copper [15], chamber treatment of steel with ODA or its mixture with BTA ensures a long protection after-effect. In this case, $120^{\circ} \mathrm{C}$ is the optimum chamber treatment temperature for the ChIn studied. In view of this, in all subsequent experiments, this temperature was used to create the adsorption films of inhibitors.

In the second series of experiments, the kinetics of formation of adsorption films by the ChIn in question was estimated under conditions of recurrent moisture condensation on the metal (Figure 1b).

In the absence of any ChIn, $\tau_{\mathrm{ct}}$ had almost no effect on $\tau_{\mathrm{pr}}$, which did not exceed $1 \mathrm{~h}$. As $\tau_{\mathrm{ct}}$ was increased from 20 to $60 \mathrm{~min}, \tau_{\mathrm{pr}}$ increased from 72 to 120 and from 120 to $168 \mathrm{~h}$ for ODA and its mixture with BTA, respectively. A further increase in $\tau_{\mathrm{ct}}$ to $2 \mathrm{~h}$ did not change the $\tau_{\mathrm{pr}}$ of steel by these ChIn. BTA did not show any appreciable protection aftereffect at any $\tau_{\mathrm{ct}}$.

Thus, there is every reason to believe that the adsorption films responsible for the PAE of the ChIn studied were formed within 1 hour of the metal chamber treatment. This $\tau_{\mathrm{ct}}$ was then used in the experiments reported below.

It is easy to notice that even under drastic conditions of daily moisture condensation, pretreatment of steel in ChIn vapors at the optimum $\tau_{\mathrm{ct}}$ and $t_{\mathrm{ct}}$ can increase the time until corrosion appears by a factor of 100 or more. In fact, the ultrathin film (indistinguishable by an unaided eye) formed upon one-hour exposure of steel in vapors of ODA or the even more efficient ODA + BTA mixture increased $\tau_{\mathrm{pr}} 120$ - or 168-fold, respectively.

The fact that ultrathin adsorption films are concerned is confirmed by ellipsometry data provided in Figure 2.

The $d$ of the air-formed oxide on steel before the chamber treatment was $3 \mathrm{~nm}$. The thermal treatment of steel in the absence of a ChIn resulted in oxide film growth. Its thickness $d$ under optimum conditions of adsorption film formation increased 5-fold, viz., to $15 \mathrm{~nm}$. BTA and ODA vapors hindered the oxide growth abruptly and the BTA+ODA arrested the oxide film growth during thermal treatment. Chamber treatment of the metal in ChIn vapors resulted in the formation of adsorption layers on the oxide film surface. Apparently, it is these adsorption layers that were responsible for the protection aftereffect. Their thickness ranged from $2 \mathrm{~nm}$ (the mixed ChIn) to $6.5 \mathrm{~nm}$ (ODA). 


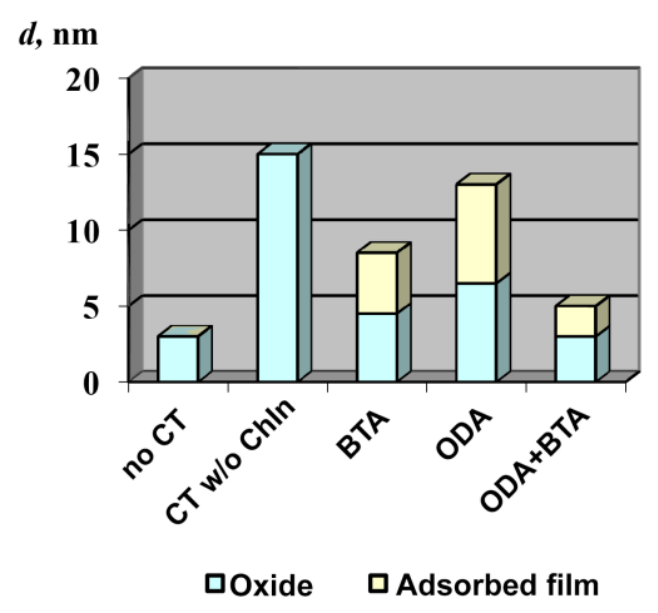

Figure 2. Effect of steel chamber treatment on the $d$ of surface films.

It is interesting that the mixed ChIn that manifested the largest PAE formed the thinnest passive film. Apparently, the structure and regularity of passive films is more important for corrosion protection than the thickness.

Like in the case of copper [15], the formation of adsorption films by ODA and its mixture with BTA resulted in the hydrophobization of the metal surface. This follows from the results of wetting angle measurements (Figure 3).

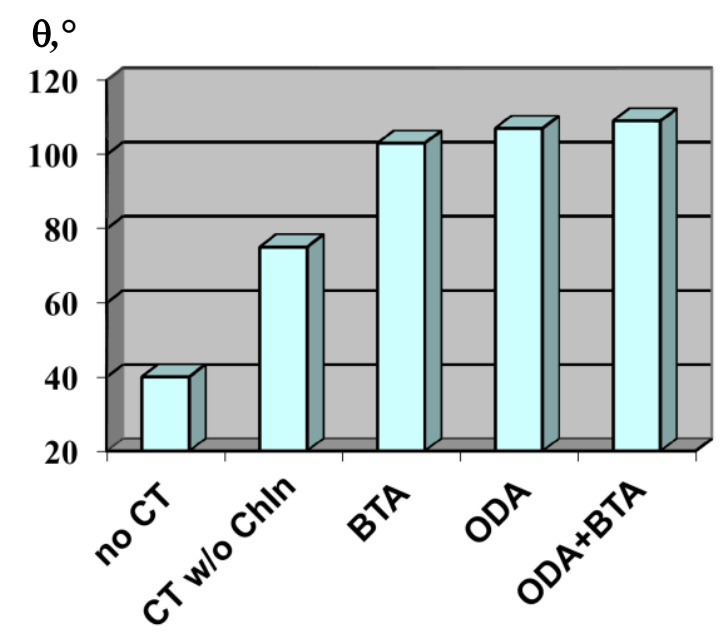

Figure 3. Effect of CT of steel on the $\theta$ of its surface.

The thermal treatment of steel hydrophobized its surface. In fact, exposure of specimens at $120^{\circ} \mathrm{C}$ in the absence of a ChIn increased $\theta$ from 40 to $75^{\circ}$. After treatment of the metal with ChIn, $\theta$ increased in the series BTA $\left(103^{\circ}\right)<$ ODA $\left(107^{\circ}\right)<$ ODA + BTA $\left(110^{\circ}\right)$, i.e., symbately to the increase in the PAE of adsorbed films in the experiments described above.

However, the corrosion under conditions of recurrent moisture condensation is of general type and occurs in the absence of corrosive anions in the environment. Corrosion 
under weathering conditions is often initiated due to local dissolution of the passive film by corrosive anions, primarily chlorides. Moreover, not all inhibitors and protection technologies aimed at the suppression of general corrosion are efficient under conditions of chloride attack. In view of this, we studied the effect of steel chamber treatment by the ChIn in question on the stability of its passive state.

The results of potentiodynamic studies presented in Figure 4 and Table 1 indicate that the adsorption films of the ChIn studied considerably stabilized the passive state of steel in the presence of chlorides, too.

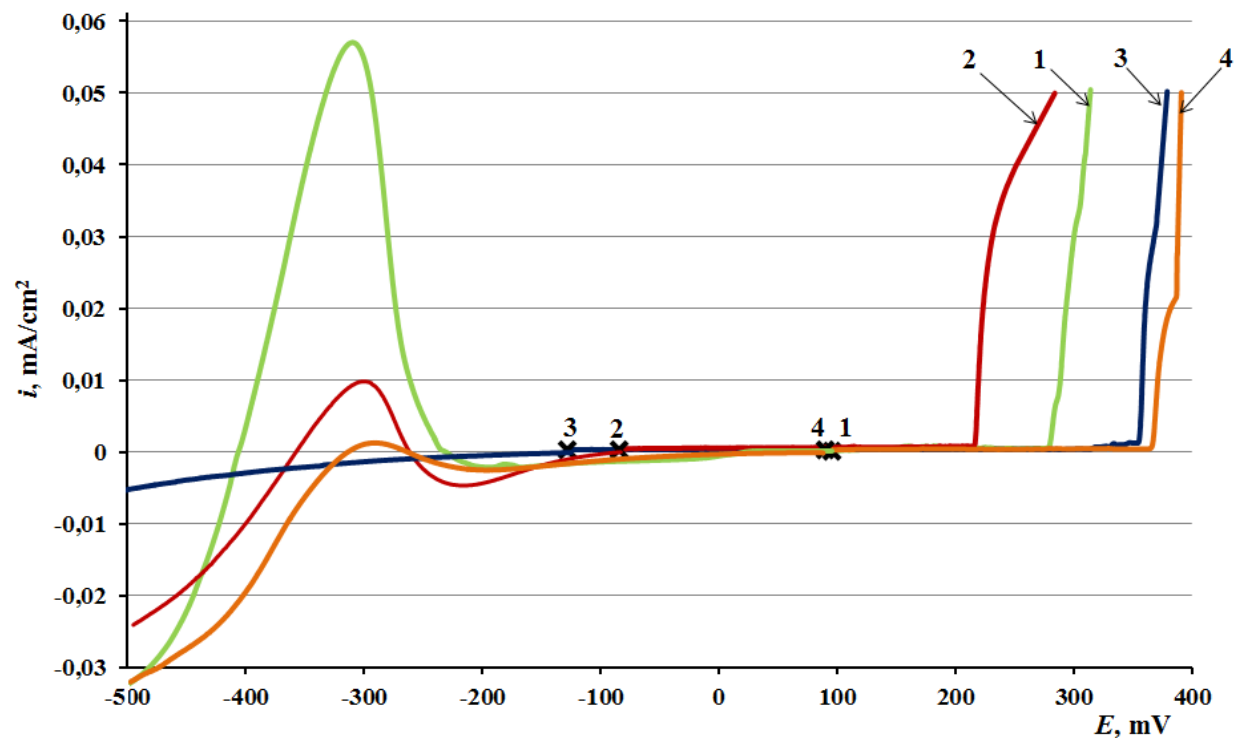

Figure 4. Polarization curves of $\mathrm{St} 3$ in borate buffer solution ( $\mathrm{pH} 7.36)$ containing $0.001 \mathrm{M}$ $\mathrm{NaCl}$. 1without treatment with a ChIn; 2BTA; 3ODA; 4ODA+BTA.

The anodic polarization curves of steel electrodes, both treated in ChIn vapors and not treated in a chamber, were typical of passive steel. The mean $E_{\mathrm{st}}$ of a steel electrode that was not treated with a ChIn amounted to $0.095 \mathrm{~V}$. Anodic polarization of steel did not result in noticeable changes in $i$ up to $E_{\mathrm{ld}}=0.150 \mathrm{~V}$. On reaching the latter potential, oscillations appeared on the polarization curves due to initiation and repassivation of local depassivation sites. Visual inspection of the electrodes removed from the electrolyte after the start of oscillations confirmed this assumption. Distinct small pits on the steel surface could be seen through a magnifying glass. Further steel polarization resulted in passive film breakdown, namely, $i$ increased abruptly at $E_{\mathrm{br}}=0.270 \mathrm{~V}$. In this case, one or more local dissolution sites visible by unaided eye formed on the metal.

The background cathodic polarization curve was characterized by an extended region (about $0.2 \mathrm{~V}$ ) where the cathodic current density $i$ only slightly depended on $E$. It was followed by a region of cathodic current density growth where reduction of the surface oxide occurred. This region was followed by an anodic loop due to active metal dissolution where $i$ reached $0.05-0.06 \mathrm{~mA} / \mathrm{cm}^{2}$. Further $E$ scanning in the cathodic direction resulted in an increase in cathodic current density again. 
Chamber treatment of steel in BTA vapors shifted $E_{\text {st }}$ by $0.180 \mathrm{~V}$ in the cathodic direction. Anodic polarization of such electrodes resulted in passive film breakdown at $E_{\mathrm{br}}$ $=0.210 \mathrm{~V}$. In this case, no $i$ oscillations preceding the breakdown were observed on the polarization curves. The shape of the cathodic polarization curve was similar to that of the background curve described above, but the active dissolution region was characterized by much lower current densities (below $0.01 \mathrm{~mA} / \mathrm{cm}^{2}$ ).

In the case of ODA, $E_{\mathrm{st}}$ shifted to more negative values $(-0.130 \mathrm{~V})$ than when steel was treated with BTA, which is a consequence of cathodic process inhibition. On anodic polarization curves, as soon as $E$ reached $0.295 \mathrm{~V}, i$ oscillations started and then the metal dissolution current increased abruptly at $0.350 \mathrm{~V}$. On cathodic polarization curves recorded after this variant of steel chamber treatment, no regions of surface oxide reduction and active metal dissolution were observed.

The mixed ChIn, unlike BTA and ODA, nearly did not affect $E_{\mathrm{st}}$, but it ennobled $E_{\mathrm{ld}}$ markedly more strongly than the individual compounds (up to $0.360 \mathrm{~V}$ ). If we take $E_{\mathrm{ld}}$ as a PAE criterion, this allows us to deem the mixed ChIn as the most efficient inhibitor for steel under the conditions of this experiment. In this case, there were no $i$ oscillations on the polarization curves. The cathodic curves were almost devoid of a metal active dissolution region.

Table 1. Effect of steel chamber treatment on the characteristics of anodic polarization curves.

\begin{tabular}{cccc}
\hline ChIn & $\boldsymbol{E}_{\text {st }}, \mathbf{V}$ & $\boldsymbol{E}_{\mathbf{l d}}, \mathbf{V}$ & $\boldsymbol{E}_{\mathbf{b r}}, \mathbf{V}$ \\
\hline No ChIn & 0.095 & 0.150 & 0.270 \\
BTA & -0.085 & 0.210 & 0.210 \\
ODA & -0.130 & 0.295 & 0.350 \\
ODA+BTA & 0.090 & 0.360 & 0.360 \\
\hline
\end{tabular}

Thus, the adsorption films of ODA or its mixture with BTA noticeably stabilized the passive state of steel by increasing its resistance against local anionic depassivation.

The data obtained allow us to assume that chamber treatment of steel with vapors of ODA or its mixture with BTA can be used in the interoperational protection of metal items. This conclusion is confirmed by the results of field corrosion tests.

The first corrosion damage (points) on steel specimens that did not undergo chamber treatment was detected after 10 days of exposure to an urban atmosphere (Moscow) under a shelter. The PAE of adsorbed BTA films is noticeably higher and amounts to 3 weeks. On the other hand, adsorbed films of ODA or its mixture with BTA ensured steel protection for a two times longer period, which may suffice for the inter-operational storage of steel items or semiproducts under similar conditions.

However, an urban atmosphere usually contains corrosive components, such as $\mathrm{SO}_{2}$ or $\mathrm{H}_{2} \mathrm{~S}$, while a shelter does not guarantee that small droplets of water would not sometimes fall on the metal items. Though the protection period in this environment is considerably 
longer than in laboratory tests with daily moisture condensation on steel specimens, longer tests are required and the chamber treatment technology needs to be perfected further.

No doubt, a further search for more efficient ChIn and advances in the technology for application of ultrathin layers would improve the reliability of steel protection from atmospheric corrosion.

\section{Conclusions}

One-hour treatment in vapors of ODA or its mixture with BTA at $t=120^{\circ} \mathrm{C}$ results in the formation of ultrathin hydrophobic adsorption films on steel that markedly improve its corrosion resistance. This kind of treatment can be used in short-term storage or transportation of steel items in order to protect them from corrosion.

\section{References}

1. P.D. Donovan, Protection of Metals from Corrosion in Storage and Transit, 1986, Ellis Horwood Limited, Chichester.

2. P.A. Schweitzer, Fundamental Metallic Corrosion: Atmospheric and Media Corrosion, 2007, New York, CRS Press.

3. A.A. Mikhailov, Yu.M. Panchenko and Yu.I. Kuznetsov, Atmospheric Corrosion and Protection of Metals, 2016, Tambov, Pershina Publishing house (in Russian).

4. I.L. Rozenfeld and V.P. Persiantseva, Atmospheric corrosion inhibitors, 1985, Moscow, Nauka (in Russian)

5. F.A. Ansari, C. Verma, Y.S. Siddiqui, E.E. Ebenso and M.A. Quraishi, "Volatile corrosion inhibitors for ferrous and non-ferrous metals and alloys: A review", Int. J. Corros. Scale Inhib., 2018, 7, no. 2, 126-150. doi: 10.17675/2305-6894-2018-7-2-2

6. N.N. Andreev and Yu.I. Kuznetsov, "Physicochemical aspects of the action of volatile metal corrosion inhibitors", Russ. Chem. Rev., 2005, 74, 8, 685. doi: 10.1070/RC2005v074n08ABEH001162

7. S. Koehler and G. Reinhard, "VCI containing package materialmode of functioning", Int. J. Corros. Scale Inhib., 2014, 3, no. 4, 286-306. doi: 10.17675/2305-6894-2014-34-286-306

8. N.N. Andreev and Yu.I. Kuznetsov, "Volatile Inhibitors of Metal Corrosion. 1. Vaporization", Int. J. Corros. Scale Inhib. 2012, 1, no. 1, 16-25. doi: $10.17675 / 2305-$ 6894-2012-1-1-016-025

9. D.M. Bastidas, E. Cano and E.M. Mora, "Volatile Corrosion Inhibitors: a Review" Anti-Corros. Meth. Mater., 2005, 52, no. 2, 71-77.

10. N.N. Andreev and Yu.I. Kuznetsov, "Volatile inhibitors of metal corrosion. II. Interaction of systems being protected with the environment and corrosion prevention conditions", Int. J. Corros. Scale Inhib., 2012, 1, no. 2, 146-153. doi: 10.17675/2305$\underline{6894-2012-1-2-146-153}$ 
11. D. Zhang, Z. An, Q. Pan, L. Gao and G. Zhou, "Volatile corrosion inhibitor film formation on carbon steel surface and its inhibition effect on the atmospheric corrosion of carbon steel", Appl. Surf. Sci., 2006, 253, no. 3, 1343-1348.

12. N.N. Andreev and Yu.I. Kuznetsov, "Volatile Inhibitors of Metal Corrosion. III. Principles and methods of efficiency estimation", Int. J. Corros. Scale Inhib., 2013, 2, no. 1, 39-52. doi: 10.17675/2305-6894-2013-2-1-039-052

13. A.I. Altsybeeva, V.V. Burlov, N.S. Fedorova, T.M. Kuzinova and G.F. Palatik, "Volatile inhibitors of atmospheric corrosion of ferrous and nonferrous metals I. Physical and chemical aspects of selection of starting reagents and synthetic routes", Int. J. Corros. Scale Inhib., 2012, 1, no.1, 51-64. doi: 10.17675/2305-6894-2012-1-1$\underline{051-064}$

14. N.N. Andreev, O.A. Goncharova and S.S. Vesely, "Volatile inhibitors of atmospheric corrosion. IV. Evolution of vapor-phase protection in the light of patent literature", Int. J. Corros. Scale Inhib., 2013, 2, no. 3, 162-193. doi: 10.17675/2305-6894-2013-2-3$\underline{162-193}$

15. A.Yu. Luchkin, O.A. Goncharova, N.N. Andreev and Yu.I. Kuznetsov, "A new method for the protection of metals from atmospheric corrosion", Praktika protivokorrozionnoi zashchity, 2017, no. 4, 7-12 (in Russian).

16. E. Kondoh, ELLIPSHEET: Spreadsheet Ellipsometry (Excel Ellipsometer), http://www.ccn.yamanashi.ac.jp/ kondoh/ellips_e.html

17. P. Atkins and J. De Paula, Physical Chemistry. Part 1, Ninth Edition, W.H. Freeman and Company, 2010. 